\title{
MEMÓRIAS SOBRE ALIMENTAÇÃO DE IDOSOS HOSPITALIZADOS
}

\author{
FOOD MEMORIES AMONG HOSPITALIZED ELDERLY PEOPLE
}

\section{MEMORIAS SOBRE ALIMENTACIÓN EN PERSONAS MAYORES HOSPITALIZADAS}

\author{
Valdenir Almeida Da Silva* \\ Maria Do Rosário De Menezes** \\ Juliana Bezerra Do Amaral *** \\ Manuela Bastos Alves**** \\ Rudval Souza Da Silva***** \\ AndrÉa Dos Santos SouZA ${ }^{* * * * * *}$
}

\section{RESUMO}

Objetivo: Analisar memórias sobre a alimentação de pessoas idosas que foram hospitalizadas em uma Unidade de Terapia Intensiva. Material e Método: Estudo qualitativo, realizado em um hospital público de Salvador, Bahia, Brasil, com quatorze pessoas idosas que foram hospitalizadas em unidades de terapia intensiva entre janeiro de 2013 e maio de 2015. Adotaram-se os seguintes critérios: ser idoso, ter permanecido na UTI por mais de 72 horas, ter se alimentado por via oral e com condiçóes cognitivas para participar de acordo com o Mini Exame do Estado Mental (MEEM). Assim, para os idosos sem escolaridade foram considerados aptos aqueles que apresentavam uma pontuação superior a 18, e 26 para aqueles com mais de oito anos de estudo. Os dados foram coletados por meio de entrevista semiestruturada e analisados através do software estatístico Alceste. Em todos os casos, foram fornecidas informaçôes sobre o protocolo da pesquisa e solicitada a assinatura do Termo de Consentimento Livre e Esclarecido. Resultados: Identificou-se a classe lexical Memórias de idosos sobre a alimentaçáo, que revela os hábitos alimentares dos idosos, os alimentos preferidos, o ritual de preparo desses alimentos; as proibiçôes sofridas pelo adoecimento crônico e a alimentação no hospital. Conclusão: A alimentação tem importante significado na vida destas pessoas idosas. Comer representa um prazer relacionado com suas memórias e identidades culturais.

Palavras-chave: Idoso; Unidades de Terapia Intensiva; Hábitos alimentares; Enfermagem.

*Enfermeiro. Universidade Federal da Bahia. Salvador, Bahia, Brasil. ORCID: https://orcid.org/0000-0003-1947-468X. Email: valdenirenf@yahoo.com.br Autor correspondente

**Enfermeira. Universidade Federal da Bahia. Salvador, Bahia, Brasil. ORCID: https://orcid.org/0000-0001-9070-8077. Email: animamen77@gmail.com

***Enfermeira. Universidade Federal da Bahia. Salvador, Bahia, Brasil. ORCID: https://orcid.org/0000-0002-7465-0183. Email: Julianabamaral@yahoo.com.br

****Enfermeira. Universidade do Estado da Bahia. Senhor do Bonfim, Bahia, Brasil. ORCID: https://orcid.org/0000-0002-40735146. Email: manu_bastos28@otmail.com

*****Enfermeiro. Universidade do Estado da Bahia. Senhor do Bonfim, Bahia, Brasil. ORCID: https://orcid.org/0000-00027991-8804. Email: rudvalsouza@yahoo.com.br

******Enfermeira. Universidade Estadual do Sudoeste da Bahia. Jequié, Bahia, Brasil. ORCID: https://orcid.org/0000-00018269-6029. Email: andreassouza75@gmail.com 


\section{ABSTRACT}

Objective: To analyze the food memories of elderly people who were hospitalized in an Intensive Care Unit (ICU). Materials and Methods: Qualitative study, conducted in a public hospital in Salvador, State of Bahia, Brazil, with fourteen elderly people who were hospitalized in intensive care units between January 2013 and May 2015. The following criteria were adopted: to be elderly, to have stayed in the ICU for more than 72 hours, to have been fed orally and have cognitive conditions to participate according to the Mini-Mental State Examination (MMSE). For the elderly without years of schooling, those with a score higher than 18 were considered suitable, and a score of 26 for those with more than eight years of schooling. Data were collected through semi-structured interviews and analyzed using Alceste statistical software. In all cases, information on the research protocol was provided and free, prior and informed consent was requested. Results: The lexical class Food Memories of the Elderly was identified, revealing the eating habits of the elderly, the preferred food, food preparation; the prohibitions caused by chronic illness and food in the hospital. Conclusion: Food has an important meaning in the lives of these elderly people. Eating represents a pleasure related to their memories and cultural identities.

Key words: Elderly people, Intensive Care Units, Eating habits, Nursing.

\section{RESUMEN}

Objetivo: Analizar los recuerdos sobre alimentos de personas mayores que fueron hospitalizadas en una Unidad de Cuidados Intensivos. Material y Método: Estudio cualitativo, realizado en un hospital público en Salvador, Bahía, Brasil, con catorce ancianos que fueron hospitalizados en unidades de cuidados intensivos entre enero de 2013 y mayo de 2015. Se aplicaron los siguientes critérios de inclusión: ser persona mayor, haber permanecido en la UTI por más de 72 horas, alimentado por vía oral y en condiciones cognitivas para participar de acuerdo al Mini Examen del Estado Mental (MEEM). Así, para aquellos sin escolaridad fueron considerados aptos los que presentaban una puntuación superior a 18, y 26 para aquellos com más de 8 años de estudio. Los datos se recopilaron mediante entrevistas semiestructuradas y se analizaron a través del software estadístico Alceste. En todos los casos, se informó sobre el protocolo de investigación y se solicitó firma del consentimiento informado. Resultados: Identificamos la clase léxica Recuerdos de los ancianos sobre los alimentos, que revela los hábitos alimentarios de los ancianos, los alimentos favoritos, el ritual de preparación de estos alimentos; Las prohibiciones que sufren las enfermedades crónicas y la alimentación en el hospital. Conclusión: La comida tiene un significado importante en la vida de estas personas mayores. Comer representa un placer relacionado con sus recuerdos e identidades culturales.

Palabras clave: Personas mayores; Unidades de cuidados intensivos; Hábitos alimentarios; Enfermería.

Fecha de recepção: 19/09/2019

Fecha de aceitação: 12/01/2021

\section{INTRODUÇÃO}

Alimentar-se é um dos atos mais essenciais do ser humano, sendo indispensável a todas as pessoas. Todo alimento é um símbolo, pois o que cada pessoa escolhe para comer revela a maneira concreta em que a realidade aparece para si própria. O comportamento alimentar é fortemente influenciado pelo contexto social. Estudos mostram que as pessoas se alimentam de acordo com as normas culturais e comem mais quando estão em companhia de amigos ou de conhecidos, do que sozinhas ou na presença de desconhecidos ${ }^{(1)}$. As escolhas do quê, quanto e como comer é influenciada pelas preferências daqueles com os quais se está conectado socialmente ${ }^{(1,2)}$.

Os requerimentos de energia e nutrientes variam de acordo com as diferenças entre as raças, 
sexo, nível de atividade física e idade. Pessoas que vivem em diferentes lugares obtêm nutrientes de distintos tipos de alimentos. Esta ideia reafirma a alimentação como elemento cultural, mais do que simplesmente motivada por requerimentos fisiológicos e bioquímicos. Assim, confirmase a alimentaçáo como um dos aspectos mais importantes da vida do ser humano. A comida, com seus simbolismos, são mais do que uma fonte de nutrição e exerce vários papeis na vida diária, nas crenças e na condição socioeconômica ${ }^{(2,3)}$.

Nesta perspectiva, entende-se que a alimentação da pessoa idosa hospitalizada não pode ser feita considerando-se apenas o aspecto fisiológico ou nutricional. $\mathrm{O}$ hospital, como organizaçáo complexa, é responsável por prover acomodação, assistência multiprofissional constante e alimentação aos pacientes, com o propósito de favorecer a recuperação da saúde destes ${ }^{(4)}$. No entanto, há uma ruptura das preferências alimentares dos pacientes em favor da dieta oferecida durante a hospitalização, sobretudo no contexto das Unidades de Terapia Intensiva (UTI).

A hospitalização na UTI leva a uma separação do contexto de vida habitual, incluindo a família e os hábitos relacionados à alimentação. Frequentemente a dieta oferecida no hospital é descrita como pouco atrativa aos sentidos e assim, pouco estimulante à ingesta. Por outro lado, uma dieta rica em nutrientes e na quantidade adequada destes é um fator diferencial para a recuperação do organismo que atravessa uma fase de estresse proporcionado pelo processo de adoecimento. Nessa fase, o organismo necessita dos nutrientes para a recuperação tecidual e para a manutenção de um nível ótimo de defesa imunológica frente a agentes infecciosos, sobretudo em pacientes idosos.

Diante disto, sabendo-se da importância da alimentação como elemento cultural e da nutrição adequada durante a hospitalização na UTI, é relevante conhecer a história alimentar e as memórias das pessoas idosas durante o período da hospitalização a fim de minimizar experiências negativas sobre os aspectos alimentares. Dessa forma, acredita-se ser possível oferecer subsídios para o planejamento e implementaçáo de cuidados que respeitem os idosos em suas histórias de vida e memórias e que assim, sejam congruentes com a cultura.

Para o entendimento de memória, parte-se do princípio de que ela é uma expressão coletiva, deixando de ser apenas individual na medida em que não coexiste de maneira isolada em uma determinada coletividade. Assim, resulta da inserção em diferentes grupos, como a família, amigos, igreja, trabalho e comunidade, de modo que são mais fortes quando que se vivencia os acontecimentos rememorados ${ }^{(5)}$. Portanto, defendese que a memória é um processo de reconstruçáo de um passado vivido e experimentado por um indivíduo pertencente a um grupo social. Como tal, possibilita a compreensáo de que o rememorar náo depende unicamente da pessoa que lembra, mas reflete uma memória coletiva ${ }^{(6)}$.

A desnutrição é comum entre pessoas acima de 65 anos, variando de 10 a 50\% entre pacientes hospitalizados ${ }^{(7)}$. A ingesta alimentar inadequada tem sido relacionada à maior morbidade, mortalidade, aumento dos custos com a saúde, risco de enfraquecimento muscular, debilidade da imunidade, depressão e declínio funcional e cognitivo $^{(7-10)}$. Estudo realizado na China com idosos em pós-operatório concluiu que a avaliaçáo precoce do estado nutricional ajuda a identificar aqueles que estáo em risco de sofrer delirium e prolongamento da hospitalização, ao passo que a oferta alimentar adequada pode atenuar tais riscos ${ }^{(7)}$.

Apesar de todas as evidências que destacam a importância do reconhecimento do estado nutricional e do aporte alimentar adequado, ainda há pouca identificação e implementaçáo do tratamento apropriado entre idosos ${ }^{(7)}$. Diante disto, enfatiza-se o papel da enfermagem no reconhecimento precoce da baixa aceitação dos alimentos pelos idosos hospitalizados, assim como o estabelecimento de cuidados para sanar tal situação. Nesta perspectiva, este artigo tem como objetivo analisar as memórias de pessoas que foram idosas hospitalizadas em Unidade de Terapia Intensiva, sobre a alimentação.

\section{MATERIAL E MÉTODO}

Trata-se de uma pesquisa qualitativa realizada com quatorzes idosos que foram hospitalizados em Unidades de Terapia Intensiva de um hospital público de grande porte, na cidade de Salvador, Bahia, Brasil. A escolha pelo campo da pesquisa 
foi baseada no perfil da clientela atendida, que engloba a população idosa, seu caráter público pertencente ao Sistema Único de Saúde (SUS), o fato de ser certificado pelos Ministérios da Saúde e da Educação do Brasil como hospital de ensino e por possuir o maior complexo de UTI do estado da Bahia.

Para a inclusão na pesquisa, adotou-se os seguintes critérios: ser idoso, ter permanecido na UTI por mais de 72 horas e ter se alimentado por via oral. Justifica-se o recorte temporal mínimo de permanência na UTI pelo conhecimento de que a partir desse tempo, as pessoas idosas ficam mais susceptíveis a prejuízos da capacidade funcional, a um maior risco de dependência de outras pessoas para as atividades diárias após a alta, à ocorrência de transtornos de humor e à sonolência durante o dia ${ }^{(11)}$ o que poderia afetar a rememoração dos acontecimentos. Além dos critérios de inclusão citados, também se considerou o período da hospitalização entre janeiro de 2013 e maio de 2015 e as condiçóes cognitivas para participar do estudo de acordo com o Mini Exame do Estado Mental (MEEM). Assim, foram considerados aptos a participar da pesquisa aqueles idosos que apresentavam uma pontuação superior a 18, para os idosos sem escolaridade e 26, para aqueles com mais de oito anos de estudo ${ }^{(12)}$.

O período da coleta de dados foi compreendido entre janeiro e maio de 2015. A coleta foi conduzida pelo pesquisador responsável o qual possui experiência em pesquisa qualitativa com idosos e em âmbito hospitalar. Realizou-se entrevista semiestruturada que foi gravada em aparelho gravador de áudio digital, mediante a anuência dos entrevistados. O conteúdo do instrumento de coleta compreendia as seguintes questóes norteadoras: conte o que você lembra sobre sua hospitalização na UTI; e conte sobre a sua experiência com a alimentação durante a sua hospitalização em na UTI. Tais questóes foram exploradas de modo a permitir aprofundamento sobre o assunto.

Em relação ao procedimento de coleta de dados, para os idosos hospitalizados entre 2013 e 2014, realizou-se a entrevista em domicílio, após o levantamento da lista de possíveis participantes, identificação dos contatos nos prontuários, agendamento das visitas e realização das entrevistas. Já as entrevistas com os idosos hospitalizados durante o ano de 2015 foram realizadas no próprio hospital, após a alta da UTI. Em todos os casos, foram fornecidas informaçóes sobre o protocolo da pesquisa e solicitada a assinatura do Termo de Consentimento Livre e Esclarecido.

Como explicitado acima, foi utilizado como critério temporal para a inclusão no estudo o tempo mínimo de 72 horas de hospitalização na UTI. Não foi definido tempo máximo de hospitalização para a coleta de dados, visto que a forma final da memória de longa duração leva em torno de três a oito horas para ser alcançada. A recuperação da memória de longa duração pode acontecer quando há lembrança de algum evento relacionado no momento de guardar a informação ou quando há relação com algo muito importante emocionalmente para a pessoa $^{(13)}$.

A quantidade de participantes foi delimitada partindo-se do princípio de que a representatividade do corpus é mais relevante do que o seu tamanho. Assim, optou-se pela finalização das entrevistas a partir do ponto em que já seria possível uma generalização das respostas ${ }^{(14)}$.

O material proveniente das 14 entrevistas foi transcrito na íntegra, conferido e passou a constituir o corpus da pesquisa, formado pelas 14 entrevistas. Esse corpus foi organizado em um banco de dados conforme as regras recomendadas para a preparação do material coletado e em seguida, procedeu-se o processamento por meio do software ALCESTE (Analyse Lexicale par Contexte d'un Ensemble de Segments de Texte), destinado à análise de dados textuais e que foi desenvolvido em 1998 por Max Reinert ${ }^{(15)}$. A utilizaçâo do ALCESTE traz como vantagem a apresentação de resultados que expressam uma visão geral de corpus volumoso de pesquisa, em um curto intervalo de tempo. O objetivo da análise com o software ALCESTE é fazer uma classificação a partir dos textos em estudo, tomando por base a distribuição das palavras em cada enunciado e, assim, apreender aquelas que são mais características. Assim, é possível distinguir classes de palavras que representam diferentes formas de discurso a respeito do objeto de estudo e descobrir as informaçóes essenciais contidas no corpus da pesquisa ${ }^{(16,17)}$.

Obteve-se um resultado considerado como satisfatório, com percentual de riqueza do vocabulário de 98,47\% e índice de pertinência igual a 79\%. O índice de pertinência está relacionado com a homogeneidade do corpus da pesquisa e 
corresponde ao percentual de aproveitamento do texto $^{(15)}$. O programa computacional utilizado procedeu à classificação em cinco grupos e seus respectivos subgrupos, os quais são chamados pelo software de classes e subclasses de enunciados significativos. Para este artigo, apresenta-se a análise da classe lexical Memórias de idosos hospitalizados sobre a alimentação e suas respectivas subclasses. Para a apresentação dos resultados, utilizaramse as Unidades de Contexto Elementar (UCE) identificadas pelo número de ordem da realização das entrevistas. As UCEs equivalem às falas dos participantes enquanto quadro perceptivocognitivo com certa estabilidade temporal, associado a um ambiente complexo ${ }^{(16,17)}$.

O projeto foi aprovado por um Comitê de Ética em Pesquisa, mediante Parecer n.o 841.527/2014 e do Certificado de Apresentação para Apreciação Ética (CAAE) n. ${ }^{\circ} 37638114.2 .0000 .5531$.

\section{RESULTADOS}

Houve igual distribuição de participantes entre ambos os sexos, a idade variou entre 64 e 82 anos, com a maior distribuição (7) entre 71 e 78 anos. Com relação à cor da pele referida, houve predominância de afrodescendentes (12). Doze dos entrevistados afirmaram viver na zona urbana, em sua maioria, em lares multigeracionais; houve predominância de idosos casados (9), com renda mensal de um salário mínimo, proveniente de aposentadoria, pertencentes à religião católica e que exerceram profissóes que não exigiam educação formal ou requeriam apenas baixa escolaridade. $\mathrm{O}$ tempo de permanência na UTI variou entre três e 36 dias. Quanto à variável clínica, as doenças cardiovasculares foram a causa predominante da hospitalização.

Os dados obtidos resultaram na construção da classe Memórias de idosos hospitalizados sobre a alimentação e de três subclasses: Memórias sobre os hábitos alimentares das pessoas idosas no cotidiano, Entre o proibido e o permitido: memórias sobre as restrições alimentares impostas pela doença, e Memórias sobre a dieta no ambiente hospitalar, as quais são apresentadas a seguir.

Memórias sobre os hábitos alimentares das pessoas idosas no cotidiano. As Unidades de Contexto Elementar (UCE) que foram agrupadas nesta subclasse mostram o significado do valor atribuído pelas pessoas idosas à alimentação. Essas UCEs revelam a força da cultura alimentar para os idosos entrevistados.

Mas em casa eu sempre compro meu leite, como meu leite, como minha farinha de aveia, de tudo; faço meu mingau; vou comendo minhas frutas. Banana a gente quase que nem compra porque tem da roça mesma (Entrevista 9).

Ai eu fui na geladeira, abri, peguei o vatapá que estava duro, ai botei uma água na panela, botei ele para aquecer, depois joguei ele dentro daquela caldaria de peixe e aquele negócio. Ai vim de lá para cá com uma concha de quiabo cortado, outra concha de efó, sambei [joguei] por cima! (Entrevista 4).

[...] Ai agora vou mandar pegar uma galinha para prender lá, para no outro dia matar para comer, ai sim. Para comer com feijáo e farinha; é comida boa! [risos] Você sabe que farinha com feijāo e uma carninha de frango é muito bom para a gente comer? É melhor do que essas comidas (Entrevista 9).

[...] é escaldado de farinha, a verdura e a carne.

[...] bote três colheres de sopa de farinha e faça um pirãozinho e coma com a verdura e a carne. [...] Depois eu vim para casa e disse assim: não está vendo que três colheres de farinha não vão dar para fazer um piráo para comer? (Entrevista 1).

Nota-se que os hábitos alimentares das pessoas idosas em seu cotidiano englobam alimentos como o mingau feito com aveia; o leite, que é consumido tanto puro, quanto com café e ainda utilizado para outras preparações; frutas, como a banana, que são produzidas pelos próprios idosos; as verduras; carnes vermelhas, carnes de galinha e ovos. A farinha de mandioca é consumida de diversas formas, desde pura, com feijão, com açúcar, e utilizada como base para pirão e escaldado. Destaca-se também a presença de elementos da culinária baiana, como o vatapá, o quiabo, a rabada, o efó e o peixe. Esses hábitos alimentares revelam a força da tradição e da cultura do meio em que vivem e do qual são produto.

Entre o proibido e o permitido: memórias sobre as restriçóes alimentares impostas pela doença. As falas destacadas a seguir dão continuidade à explicitação da importância dos hábitos alimentares para as pessoas idosas. Destacam o movimento 
entre o desejo, a forma de preparo do alimento que gostariam de comer e as restriçóes. Também revelam o valor da farinha de mandioca como alimento essencial na cultura alimentar desses idosos.

Ai a médica me disse assim: se a senhora comia farinha, de hoje em diante a senhora náo coma mais, eu acho que é por isso que seu açúcar não baixa (Entrevista 1).

Está tudo bem; estou viva! Ai... Um sufoco! Era a fase pior, era comer aquela comida [do hospital] [...] Mas é porque eu gosto de comer pimenta, de vez em quando eu como uma pimentinha... (Entrevista 1).

Eu tenho vontade de comer muito é pimenta, mas eu tenho medo; mas que eu gosto, eu gosto! Mas eu tenho medo de comer. Eu chego aos pés de pimenta, lá na roça, na minha casa, a boca enche d'água, eu digo ô meu Deus! Dá vontade de pegar assim e engolir [risos], mas não posso... (Entrevista 1). Em casa eu náo como, náo [dieta do hospital], tenha paciência! Eu saio de casa [...] para comprar o peixe bulindo, ó, na canoa, o peixe está assim ó... [peixe vivo, fresco, ainda se mexendo] (Entrevista 4).

Frango eu como, carne de frango, daquelas outras galinhas caipiras, mas essas galinhas de granja, eu não como, Deus me livre! Como não. O que eu como mais é carne de vaca, carne de carneiro; eu gostava também de comer carne de porco, mas eu sei que náo vou comer mais, não; carne de porco eu sei que não vou comer mais, não. (Entrevista 9) Fazer aquele escaldado, aquele... Poxa... Isso ai eu náo como de garfo porque me atrapalha, comer bomf, bomf [fazendo gesto de comer com a mão]. Nada disso eu posso fazer mais. (Entrevista 4)

Para além dos ingredientes básicos, como a farinha, o modo de preparo e a quantidade são essenciais para a satisfação. A convivência com as restriçóes tem um significado de incompletude. Identifica-se que, não obstante a memória da cultura alimentar, no grupo de idosos pesquisados estarem muito viva no que diz respeito aos seus componentes, também é notória a forma de preparação. A comida, preparada aos seus modos, acrescentava sabor e sentido às suas vidas.

Memórias sobre a dieta no ambiente hospitalar. As memórias das pessoas idosas sobre a dieta no hospital são permeadas pelo sentimento de satisfação, pelo acostumar-se a comer, pelas diferenças da alimentação habitual e pela inapetência. É frequente, nesta subclasse, expressóes como fastio, falta de fome, falta de apetite, dor e mesmo as lembranças sobre as condiçóes do ambiente hospitalar, como odor e a presença de pessoas com feridas.

A alimentação, eu sou boa de comer, não tenho o que comentar, não. Alimentava-me... Sentia fome... Tinha vez que eu estava com fastio, mas eu comia assim mesmo, tivesse fome que não tivesse, eu estava comendo (Entrevista 11).

Mesmo sem sentir fome, não sentia fome de jeito nenhum, comia a pulso [sem vontade de comer], mas não sentia fome; era falta de apetite, era o corpo todo doendo. Essas coisas que eu sentia (Entrevista 11).

Um mau cheiro [no hospital], aquele povo com aquelas... Cheios de feridas, meu Deus do céu, por isso que eu não como mais carne. Não aguentei olhar para aquelas coisas [as feridas]. Misericórdia! Deus é mais! Estou com o meu estômago muito ruim (Entrevista 9).

Eu vou te contar: comida sem sal, meu irmão, é um purgante! Eles [no hospital] têm uma mania de dar carne triturada, sabe, pegava o frango, cozinhava. O tempero, todo estranho (Entrevista 4).

$O$ purê era o que eu comia. Ontem que me veio aqui um peixe, eu comi porque afinal de contas... Pareceu que esqueceram o peixe fora da geladeira, não sei; aquilo desfiado... Fazer o quê? O que é isso?! Não estou em casa... (Entrevista 4).

No hospital, a precisão dietética é adaptada à condição clínica de cada paciente e permeada por restrições, adquirindo status terapêutico. Assim, são frequentes, em UTI, dietas hipossódicas, hipolipídicas, hipoglicídicas, hipotrotéicas; e ainda, suas variaçóes adaptadas a pessoas cardiopatas, diabéticas, nefropatas, hipertensas e hepatopatas. Predomina, contudo, o controle da quantidade de alimentos e do volume de líquido a ser ingerido.

O fastio associa-se à repugnância ou aversão, no contexto dos fragmentos destacados. Por vezes, relaciona-se à própria condição clínica, que não lhes permite comer como deveria, mas também lembra o cheiro do hospital, os odores desagradáveis exalados do ambiente e de feridas infectadas de outros pacientes. A comida de hospital, ou dieta hospitalar, é qualificada tanto com adjetivos positivos quanto negativos. 


\section{DISCUSSÃO}

A alimentação pode ser entendida pela vertente biológica e pela cultural. No que diz respeito à biologia, os alimentos ajudam a manter a vida e é condição indispensável à sobrevivência. Por meio da assimilação dos nutrientes, mantém-se a vitalidade e a fisiologia. Alguns elementos como a idade, peso, altura, padrão de atividade física e presença de doenças interferem na escolha e na quantidade de alimentos ingeridos ${ }^{(8,18)}$. $\mathrm{O}$ ato de comer, para as pessoas idosas entrevistadas, está além do comer como algo mecânico e sem significado social. Para além dos ingredientes básicos, o modo de preparo e a quantidade são essenciais para a satisfação. A convivência com as restriçóes alimentares tem um significado de incompletude, de ato não realizado completamente e que não satisfaz.

$\mathrm{Na}$ vertente cultural, englobam os alimentos preferidos, permitidos, proibidos e suas escolhas são determinadas por fatores como gênero, identidade, família, religião e memória. Pode-se afirmar que comer é uma atitude simbólica e cultural e assim localiza-se para além das necessidades fisiológicas e da sobrevivência. A necessidade de sobrevivência pelo consumo alimentar vem depois da ingesta, já as questões simbólicas antecedem-na. Se a natureza produz os alimentos, a cultura produz códigos por meio dos cardápios, receitas e hábitos ${ }^{(8,9,18,19)}$.

O comer incorpora tanto os alimentos quanto os seus significados, configurando uma troca simbólica e elementos capazes de expressar a posição de um agente social em suas relações com o cotidiano. A alimentação possui relaçóes claras com a cultura local, a religião, os simbolismos e a identidade. A seleção dos alimentos é baseada nas culturas, que envolve crenças e tradiçóes; na moral, uma vez que consideram critérios étnicos, políticos, ecológicos, ambientais e éticos; e na racionalidade, baseada na escolha a partir de critérios científicos voltados para a manutenção de uma aparência física e do estado de saúde ${ }^{(20)}$. Assim, torna-se importante compreender a alimentação não somente pelo ponto de vista fisiológico, mas também pelos fatores simbólicos, de heranças culturais, memórias afetivas e pela sociabilidade $\mathrm{e}^{(8,9,18)}$.

Nota-se que os hábitos alimentares das pessoas idosas, em seu cotidiano, englobam alimentos como o mingau feito com leite e aveia, e frutas, como a banana, que são cultivadas pelos próprios idosos.
A farinha de mandioca é consumida de diversas formas: pura, com feijão, com açúcar, e utilizada como base para pirão e escaldado. Destaca-se também a presença de elementos peculiares da culinária baiana, como a pimenta, o vatapá, o quiabo, o efó e o peixe. Esses hábitos alimentares revelam a força da tradição e da cultura do meio em que vivem e do qual são produto.

Os idosos que concederam as entrevistas quatro e nove possuem como peculiaridade em comum o gosto por preparar a própria comida e comer segundo seus costumes. Revelam o poder de preservar a própria identidade cultural, mantendo seus hábitos e preferências. Reflete ainda o senso de independência, o prestígio atribuído à habilidade de cozinhar, a memória, cultura familiar ou de uma raça. Para os idosos, a comida classificada como boa e saborosa é aquela preparada em casa. Informação semelhante também é encontrada em estudos realizados em outros países, como Canadá( ${ }^{(8)}$ e Noruega ${ }^{(9)}$. Dessa forma, a comida pode se constituir como um elemento que favorece a manutenção de identidade e o auto reconhecimento dos idosos como pertencentes a um grupo ou comunidade. Em contraposição, a comida do hospital é tida como ruim devido à falta de sabor.

$\mathrm{O}$ inconformismo dos participantes, presente na segunda subclasse é demonstrado pelas expressóes como “tenha paciência!” e “espera aí [...], está errado [...], não botar tempero nem nada...”. Segundo o entendimento desse idoso, não é possível se alimentar com qualidade sob tantas restriçôes. Para uma pessoa que, como ele, compra um peixe ainda vivo, "bulindo" na canoa; que prepara o próprio alimento com o tempero a seu gosto, viver com tantas proibições é uma tarefa árdua. Tal missão só é amenizada, acredita-se, devido à existência de um sentido maior, que é a esperança de viver mais, com saúde e entre os seus.

Também cabe destacar o significado do ato de comer na UTI, para as pessoas idosas. Diante das singularidades dos idosos no que diz respeito aos seus hábitos alimentares, a diferença entre o tipo de alimento, por si só, já poderia causar desconforto e inibição do apetite. Indo além, comer na UTI é um ato solitário e impessoal, visto que é feito na presença de pessoas desconhecidas e longe dos familiares. Sabe-se que, por vezes, na UTI, o alimento é servido já frio, com consistência e sabores que não agradam e sem ajustes aos hábitos dos idosos. Destaca-se 
também que é comum o alimento ser servido em embalagens frágeis acompanhado de talheres de plástico, igualmente delicados, que dificultam o manuseio. Em contraposição, alguns idosos não têm o hábito de comer com talheres porque usavam somente as mãos para se alimentar. Para eles, o ato de comer com as máos significa manipular, sentir e saborear os alimentos, imprimindo maior satisfação aos sentidos.

Ao se relacionar a alimentação com o envelhecimento, chega-se à convergência entre o corpo envelhecido que pode sofrer com Doenças Crônicas não Transmissíveis (DCNT) e a importância da alimentação para o controle de tais patologias. Daí decorre o fato de que, com o envelhecimento ocorrem limitaçóes fisiológicas, com alteraçôes no processo mastigatório e digestório, além das DCNT, que definem o repertório alimentar do idoso. Outras questóes também podem ser relacionadas, como a mobilidade, autonomia, condição financeira e a composição familiar ${ }^{(8-10,19)}$.

Pesquisa sobre o comportamento de consumo de alimentos em famílias de baixa renda no Mato Grosso do Sul, Brasil, encontrou como resultado que o preço é o requisito mais importante para a escolha alimentar, seguido pelas questóes relacionadas à saúde e sabor. Os alimentos preferidos foram arroz e feijão, carnes, frutas, frituras, macarrão, ovo e leite. A pesquisa destaca também os benefícios dos alimentos para a saúde, levando a contrabalançar os recursos financeiros disponíveis e a fazer escolhas saudáveis dentro das possibilidades. Dentre os idosos, as escolhas são baseadas no menor consumo de gorduras, açúcares e sal ${ }^{(21)}$. Em estudo realizado no Chile, os idosos reconheceram os alimentos que consideram nocivos para a saúde e afirmam preferir alimentos mais naturais. Os alimentos preferidos são o leite, cereais, verduras e legumes ${ }^{(22)}$.

Interpreta-se, a partir das UCEs, que os idosos revelaram um sentimento de satisfação com a dieta, tanto em termos de quantidade quanto em variedade. Para eles, a dieta oferecida estava adequada ao momento pelo qual passavam e não era necessário ajuste. A presença de doenças crônicas e a hospitalização impõem às pessoas idosas o convívio com restriçóes alimentares e a inevitável aceitação de uma nova dieta.

Diante das restriçóes alimentares, há uma perda do sentido do alimento, pois este passa a se distanciar das preferências pessoais e se aproximar da "comida de doente". Enfatiza-se também a influência das crenças, padróes e simbologias atribuídos aos alimentos e aos hábitos alimentares pelas pessoas idosas. É importante quantificar as necessidades nutritivas que as pessoas idosas necessitam, mas também considerar a história de vida das pessoas e suas influências nas preferências alimentares ${ }^{(8,9,22)}$.

Autores destacam que o preconceito com a alimentaçâo hospitalar pode levar a uma baixa ingesta nutricional durante a hospitalização e à desnutrição in trahospitalar. $\mathrm{O}$ sal possui uma relação simbólica com a cultura alimentar por ser de fácil acesso, ter baixo custo e pelo sabor adicionado ao alimento. Outros fatores influenciam na aceitação da dieta hospitalar, como cor, forma, variedade, quantidade, aroma, textura, temperatura, horário de distribuição, ambiente onde a refeição é realizada, dentre outros ${ }^{(8-10,23,24)}$.

Um maior tempo de internação leva a uma menor aceitação da dieta hospitalar. Pessoas idosas estão em maior risco de má nutrição quando doentes. A admissão no hospital afeta o estado nutricional destas pessoas e, assim, recomenda-se uma adequação entre a prescrição dietética e as restriçóes alimentares dos pacientes, com vistas ao oferecimento de refeiçóes que sejam saborosas e atrativas $^{(23,24)}$.

A ciência moderna centrada no modelo cartesiano, não valoriza os aspectos subjetivos, sensoriais, afetivos e culturais das pessoas, uma vez que eles não são objetos de mensuração e de explicação pela racionalidade científica. Os desejos, as memórias, as histórias de vida e a cultura local são vistos como obstáculo à racionalidade científica. Nesse sentido, autores ${ }^{(20,25)}$ lançam críticas à terapêutica nutricional, centrada nas quantidades e nos horários em que as dietas devem ser servidas, com vistas à minimizaçáo de riscos de adoecimento. Seguindo-se esse raciocínio, o ser humano não é visto em sua completude e como pertencente a uma sociedade. Além disso, o aspecto cultural da comida é suplantado pela fragmentação disciplinar própria do paradigma científico vigente.

A consideração da subjetividade, histórias de vida, relações afetivas e familiares e as dimensóes culturais, permeadas pelo contexto político e econômico vâo no sentido de um entendimento mais amplo dos fatores que influenciam a saúde das pessoas ${ }^{(8,25)}$. As memórias dos idosos sobre a 
alimentação são permeadas pela memória afetiva e olfativa, com lembranças de cheiros e sabores das comidas do passado, as modificaçóes na alimentação ocorridas com a modernização e as prescriçóes nutricionais. No entanto, a perspectiva nutricional se torna predominante na vida do idoso pela submissão ao discurso da importância da dieta para a manutenção da saúde, devido à maior frequência dos idosos nos serviços de saúde e pelo acesso às informaçóes propagadas pelos meios de comunicação, como notícias de descobertas científicas ou como apelos publicitários ${ }^{(19)}$.

A terapêutica nutricional, fundamentada em uma racionalidade científica que visa à cura e a busca por um estado de saúde dito como normal, estabelece um conceito normativo e idealizado de alimentação saudável. Nesse bojo, a alimentação tem conotação dietoterápica e de medicamento, de acordo com necessidades individuais, com recomendação de moderação e controle na ingesta alimentar. Assim, os alimentos são vistos de forma separada do contexto cultural e das práticas diárias das pessoas, atendendo apenas às demandas fisiológicas e idealizadas ${ }^{(20,25)}$. Isso leva a inferir que, para os idosos, comer no hospital é um desafio, um sacrifício, e a comida é um "purgante". Representaçôes negativas sobre a comida de hospital também é encontrada em pesquisas realizadas em outros países ${ }^{(8,9)}$. Essas questões são amparadas principalmente pelas diferenças no modo de preparo, no sabor, na falta de apetite, no comer sem sentir fome, nas interferências de medicamentos e de patologias, podendo levar a consequências como o prolongamento da hospitalização e a desnutrição ${ }^{(8-10)}$. Entende-se que é preciso manter ou resgatar o prazer de comer que deve se estender também ao hospital, possibilitando bem-estar e satisfação aos idosos.

Estudo $^{(19)}$ sobre concepções de alimentação saudável em uma universidade aberta da terceira idade no Rio de Janeiro identificou que o discurso dos idosos sobre a alimentação saudável era permeado pelo acúmulo das experiências vividas e pelo reconhecimento das modificaçóes impostas pelo envelhecimento sobre os hábitos alimentares. Daí decorre a percepção das restriçóes e do que é tolerável pelo próprio organismo. Os idosos relataram a exclusão de o repertório alimentar de comidas descritas como pesadas, gordurosas, de difícil digestão e que fazem mal. Esta ideia pode ser exemplificada pela reprodução da fala de um profissional médico que foi taxativo em sua prescrição da proibição de comer farinha. De tal modo, a sujeiçáo à norma externa da comida saudável se destaca como uma forma de manter a saúde. Isso revela um conflito com a norma interna, definida pelos gostos pessoais, pois a exclusão dos alimentos preferidos custa certa pesar.

No entendimento dos idosos, uma comida saudável é aquela que tem fácil digestão, que não representa perigos ao organismo, com adequação nutricional e na forma de preparo, podendo ser consumida sem receios. Assim, revelam e percepção do próprio corpo permeada pela assimilação de valores simbólicos modernos ligados à praticidade e funcionalidade ${ }^{(19)}$. Fatores como doença e falta de independência estão associadas a risco nutricional entre idosos possivelmente associado à redução do paladar, olfato, visão, condição dentária e alteraçôes na mastigação, no poder aquisitivo e na habilidade de preparar a própria alimentação ${ }^{(9,26)}$.

As críticas a esse modelo único e normativo de comer seguem no sentido de que um padrão de alimentação único, sem consideraçốes ao conjunto de representaçóes de um grupo social, seus desejos, histórias de vida, prazeres cotidianos, afetos e compulsóes reduz a pessoa a um ser que come calorias e nutrientes, sem a devida valorização da comida como símbolo de pertencimentos diversos ${ }^{(25)}$.

O discurso da alimentação benéfica e de um ideal de corpo estabelece como padrão saudável quem se alimenta conforme as normas estabelecidas. Apesar de buscar melhores condições de saúde, também expressa rigidez de pensamento ao não se analisar outras lógicas para nortear a adaptação de hábitos, comportamentos e práticas alimentares ${ }^{(25)}$.

A busca pelo émic, ou seja, a visão interior da cultura alimentar dos idosos, somada ao esforço profissional pela sua compreensão, favorece o estabelecimento do cuidado culturalmente congruente ${ }^{(27)}$, com menos choques e descontentamentos, e mais satisfação e diálogo entre enfermeiros, idosos e familiares.

A pesquisa qualitativa requer cautela quanto à generalizaçáo dos resultados para outras populaçóes ${ }^{(28,29)}$. No entanto, pode-se afirmar que, a despeito desta investigação ter sido conduzida em apenas um local e ser fundamentada nas afirmaçóes dos idosos para a análise dos acontecimentos 
rememorados, a profundidade das respostas obtidas permite entender como as experiências são vivas e salutares nas memórias levando à compreensão da importância da alimentação para as pessoas idosas. Assim, embora as vivências do adoecimento, hospitalização na UTI e com a alimentação sejam subjetivas e únicas, é preciso valorizar o contexto cultural de cada pessoa para se alcançar a transculturalidade do cuidado da enfermagem ${ }^{(8,}$ 9, 30).

\section{CONCLUSÓES}

Após a análise das memórias de pessoas idosas que foram hospitalizadas em UTI, sobre a alimentação, conclui-se que a comida tem forte simbologia na fala dos participantes. É rememorada como ato intrínseco à identidade cultural cotidiana e que atribui sentido ao viver. Os resultados também revelaram os conflitos que emergiram a partir do surgimento de doenças que impuseram restriçóes alimentares e da ingestáo de dietas no ambiente hospitalar. Assim, pode-se afirmar que o comer assume significado simbólico na vida das pessoas idosas hospitalizadas. Comer era, para elas, um prazer relacionado com suas memórias e identidades. A comida, preparada aos seus modos, acrescentava sabor e sentido às suas vidas. A equipe de enfermagem atua, então, como educadora, utilizando-se de estratégias de comunicação que facilitem a compreensão das necessidades de mudanças dos hábitos alimentares, pelas pessoas idosas.

A integração de saberes pelos enfermeiros, quando do planejamento dos cuidados às pessoas idosas, requer um pensamento crítico e amplo. No caso específico de alteração da alimentação, é importante que sejam consideradas as informaçóes obtidas a partir da história de vida, alimentar e

\section{REFERÊNCIAS}

1. Higgs S, Thomas J. Social influences on eating. Current Opinion in Behavioral Sciences. [Internet] 2016 [citado 2017 out 16]; 9:1-6. Disponível em: http://dx.doi.org/10.1016/j.cobeha.2015.10.005

2. Pantoja CT. Patrimonio gastronómico en perso- clínica, com a própria pessoa idosa; informaçóes dos familiares; além da experiência profissional e dos conhecimentos fundamentais da enfermagem gerontológica. Um dos caminhos a ser seguido, frente à necessidade da nutrição adequada no hospital, é a busca por uma individualização da dieta hospitalar com o cotidiano das pessoas idosas hospitalizadas, sempre que possível.

Destaca-se a atuação da equipe de enfermagem no cuidado com o ambiente durante as refeições, visando minimizar aspectos que possam interferir negativamente na aceitação da dieta, como dores, odores, barulhos, excesso de pessoas, e a realização de procedimentos clínicos. Também é importante pensar na presença de familiares ou pessoas significativas durante as refeiçóes a fim de estimular a aceitação da dieta. Um desafio para a enfermagem é dar um sentido às açóes de educação em saúde, voltadas para a alimentação. Ou seja, utilizar-se de estratégias que conduzam à compreensão do porquê de determinadas restriçóes alimentares e à impressão de um novo sentido à vida a partir da vontade do viver saudável. Para tanto, é necessário um trabalho multiprofissional, envolvendo também os nutricionistas.

A experiência dos pesquisadores como enfermeiros hospitalares e em Unidade de Terapia Intensiva favoreceu a interpretação dos resultados. A prática da enfermagem intensivista é marcada pela assistência às pessoas idosas que trazem consigo diversas necessidades, dentre elas os cuidados específicos com vistas à aceitação da alimentação. Um dos riscos de vieses da pesquisa foi a análise dos resultados com base na própria experiência, em detrimento dos achados. Para tanto, optou-se por coletar os dados em um hospital no qual os pesquisadores não atuam e para a interpretação, realizou-se fundamentação teórica ampla e o diálogo com outros estudos semelhantes já publicados, tanto em âmbito nacional quanto internacional. 
org/10.1016/j.jef.2015.11.004

4. Godoy AM, Lopes DA, Garcia RWD. Transformaçóes socioculturais da alimentação hospitalar. Hist cienc saúde-Manguinhos [Internet]. 2007 [citado 2021 jan 12]; 14(4): 1197-1215. Disponível em: https://doi.org/10.1590/S010459702007000400006.

5. Silva GF. A memória coletiva. Aedos [Internet]. 2016 [citado 2021 jan 12]; 8(18): 247-253. Disponible en: https://seer.ufrgs.br/aedos/article/view/ 59252/38241

6. Halbwachs M. A memória coletiva. Tradução de Beatriz Sidou. 2a ed. São Paulo: Centauro, 2013. $222 \mathrm{p}$.

7. Zhao Y, Xia X, Xie D, Liao Y, Wang Y, Chen L et al. Geriatric Nutritional Risk Index can predict postoperative delirium and hospital length of stay in elderly patients undergoing non-cardiac surgery. Geriatr Gerontol Int [Internet]. 2020 [citado 2021 jan 12]; 20(8): 759-764. Disponível em: https:// doi.org/10.1111/ggi.13963.

8. Trinca V. Putting Quality Food on the Tray: Assessing Patients' Expectations and Experiences of Meals Served in Sixteen Ontario Hospitals [Thesis en Internet]. Master of Science In Kinesiology. University of Waterloo. 2020 [citado 2021 jan 12]. Disponível em: https://uwspace.uwaterloo.ca/ bitstream/handle/10012/16399/Trinca_Vanessa. pdf?sequence $=3 \&$ isAllowed $=y$

9. Hestevik CH, Molin M, Debesay J, Bergland A, Bye A. Older patients' and their family caregivers' perceptions of food, meals and nutritional care in the transition between hospital and home care: a qualitative study. BMC Nutrition [Internet]. 2020 [citado 2021 jan 12]; 6: 11. Disponível em: https:// doi.org/10.1186/s40795-020-00335-w

10. Wright C, Shankar B, Marshall S, Pearcy J, Somani A, Agarwal E. Prevalence of malnutrition risk and poor food intake in older adults in Indian hospitals: a prospective observational nutrition day study with novel mapping of malnutrition risk to the malnutrition screening tool. Nutrition \& Dietetics [Internet]. 2020 [citado 2021 jan 12]; 77(44): 1-10. Disponível em: doi: 10.1111/17470080.12641 .

11. Jesus FS, Paim DM, Brito JO, Barros IA, Nogueira TB, Martinez BP, et al. Declínio da mobilidade dos pacientes internados em unidade de terapia intensiva. Rev Bras Ter Intensiva [Internet]. 2016 [citado 2021 jan 12]; 28(2): 114-119. Disponível em: doi: 10.5935/0103-507X.20160025.

12. Ministério da Saúde (Br). Envelhecimento e saúde da pessoa idosa. Cadernos de Atençáo Básica n. ${ }^{\circ}$ 19. Brasília: Ministério da Saúde, 2006 [citado 2021 jan 12]. Disponível em: http://bvsms.saude. gov.br/bvs/publicacoes/evelhecimento_saude_ pessoa_idosa.pdf

13. Izquierdo I, Miskiw JC, Furini CRG. Biologia do aprendizado e da memória. In: Quevedo J, Izquierdo I. Neurobiologia dos transtornos psiquiátricos. [Internet] Porto Alegre: Artmed, 2020 [citado 2021 jan 12]. Cap. 8. 3880.

14. Swedish Agency for Health Technology Assessment and Assessment of Social Services (SBU). Evaluation and synthesis of studies using qualitative methods of analysis [Internet]. Stockholm: SBU; 2016 [citado 2021 jan 11]. Disponível em: https://www. sbu.se/globalassets/ebm/metodbok/sbuhandbook_ qualitativemethodsofanalysis.pdf

15. Azevedo DM, Costa RKS, Miranda FAN. Uso do ALCESTE na análise de dados qualitativos: contribuiçóes na pesquisa em enfermagem. Rev enferm UFPE on line [Internet]. 2013 [citado 2021 jan 11]; 7(esp): 5015-22. Disponível em: doi: 10.5205/reuol.4700-39563-1-ED.0707esp201326

16. Amaral-Rosa MP. Considerations on the use of IRAMUTEQ software for qualitative data analysis. Rev Esc Enferm USP [Internet]. 2019 [cited 2021 jan 11]; 23(53):e03468. doi: 10.1590/S1980220X2019ce0103468.

17. Canuto A, Braga B, Monteiro L, Melo R. Critic aspects of CAQDAS usage in qualitative research: an empiric comparison of ALCEST and IRAMUTEQ as digital tools. CIAIQ [Internet]. 2020 [citado 2021 jan 11]; 9: 198.211. Disponível em: DOI: https://doi.org/10.36367/ntqr.3.2020.199-211

18. Lima RS, Ferreira Neto JA, Farias RCP. Alimentação, comida e cultura: o exercício da comensalidade. Demetra [Internet]. 2015 [citado 2017 out 16]; 10(3): 507-522. Disponível em: https://doi.org/10.12957/demetra.2015.16072

19. Kuwae CA, Carvalho MCVS, Prado SD, Ferreira FR. Concepçôes de alimentação saudável entre idosos na Universidade Aberta da Terceira Idade da UERJ: normas nutricionais, normas do corpo e normas do cotidiano. Rev Bras Geriatr Gerontol [Internet]. 2015 [citado 2021 jan 11]; 18(3): 621-630. Disponível em: https://doi. org/10.1590/1809-9823.2015.14224.

20. Azevedo E. Alimentaçáo, sociedade e cultura: temas contemporâneos. Sociologias [Internet]. 2017 [citado 2021 jan 11]; 19(44): 276-307. Disponível em: http://dx.doi.org/10.1590/15174522-019004412

21. Defante LR, Nascimento LDO, Lima-Filho DO. Comportamento de consumo de alimentos de famílias de baixa renda de pequenas cidades brasileiras: o caso de Mato Grosso do Sul. Interaçôes [Internet]. 2015 [citado 2021 jan 11]; 16(2): 265-276. Disponível em: http://dx.doi. org/10.1590/151870122015203. 
22. Pantoja CT, Riveros MA, Placencia JPA, Castro MS, Roa MM, Placencia AA. Significancia del valor simbólico de los alimentos en personas mayores. Nutr clin diet Hosp [Internet]. 2018 [citado 2021 jan 11]; 38(1): 10-14. Disponível em: 10.12873/381CTroncoso

23. Best $\mathrm{C}$, Hitchings $\mathrm{H}$. Improving nutrition in older people in acute care. Nurs Stand [Internet]. 2015 [citado 2021 jan 11]; 22; 29(47): 50-7. Disponível em: 10.7748/ns.29.47.50.e9873.

24. Filipini K, Gomes CC, Carvalho APPF, Vieira LL. Aceitação da dieta hipossódica com sal de cloreto de potássio (sal light) em pacientes internados em um hospital público. Revista de Atenção à Saúde RAS [Internet]. 2014 [citado 2021 jan 11]; 12(41): 11-18. Disponível em: https://doi.org/10.13037/ rbcs.vol12n41.2093

25. Kraemer FB, Prado SD, Ferreira FR, Carvalho MCVS. O discurso sobre a alimentação saudável como estratégia de biopoder. Physis [Internet]. 2014 [citado 2021 jan 11]; 2(4): 1337-1359. Disponível em: http://dx.doi.org/10.1590/S010373312014000400016
26. Peura-Kapanen L, Jallinoja P, Kaarakainen M. Acceptability of convenience food among older people. SAGE Open [Internet]. 2017 [citado 2021 jan 11]: 7(1): 1-11. Disponível em: https://doi. org/10.1177/2158244017698730

27. Clarke S. Cultural congruent care: A Reflection on patient outcome. J Healthc Commun [Internet]. 2017 [citado 2021 jan 11]; 2(4): 51. Disponível em: 10.4172/2472-1654.100092

28. Johnson JL, Adkins D, Chauvin S. Qualitative research in pharmacy education. A review of the quality indicators of rigor in qualitative research. AJPE [Internet]. 2020 [citado 2021 jan 11]; 84(1): 138-146. Disponível em: http://www.ajpe.org

29. McGinley S, Wei W, Zhang L, Zheng Y. The state of qualitative research in hospitality: a 5-year review 2014 to 2019. Cornell Hospitality Quarterly [Internet]. 2021 [citado 2021 jan 11]; 62(1): 8-20. Disponível em: 10.1177/1938965520940294

30. Wehbe-Alamah H, McFarland M. Leininger's Ethnonursing Research Method: Historical Retrospective and Overview. JTCN [Internet]. 2020 [citado 2021 jan 11]; 31(4): 337-349. Disponível em: $10.1177 / 1043659620912308$ 